\title{
Synthesis of Sulphanylamides from New Derivatives of Aminopyrazoles
}

Ilya G. Povarov, Viktor V. Efimov, Alexey V. Lyubyashkin, Anna S. Kositsyna, Georgy A. Suboch and Mikhail S. Tovbis* Reshetnev Siberian State University of Science and Technology 31 Krasnoyarsky Rabochy, Krasnoyarsk, 660037, Russia

Received 23.12.2018, received in revised form 29.12.2018, accepted 01.04.2019

For the newly synthesized 3-aryl-5-methoxymethyl-4-amino-1H-pyrazoles the sulfonylation reaction of the amino group by p-acetamidobenzenesulfonyl chloride was carried out. As a result, sulfanilamide derivatives of substituted aminopyrazoles identified using $N M R^{1} H$, IR spectroscopy and mass spectrometry were obtained for the first time.

Keywords: Pyrazole, aminopyrazole, sulfonylamide, sulfonylation, $N M R^{1} H$, IR spectroscopy, mass spectrometry.

Citation: Povarov I.G., Efimov V.V., Lyubyashkin A.V., Kositsyna A.S., Suboch G.A., Tovbis M.S. Synthesis of sulphanylamides from new derivatives of aminopyrazoles, J. Sib. Fed. Univ. Chem., 2019, 12(2), 240-247. DOI: 10.17516/1998-2836-0122.

(C) Siberian Federal University. All rights reserved

* Corresponding author E-mail address: povarovi@mail.ru, tovbis@bk.ru 


\title{
Получение сульфаниламидов
}

\section{на основе новых производных аминопиразолов}

\author{
И.Г. Поваров, В.В. Ефимов, А.В. Любяшкин, \\ А.С. Косицына, Г.А. Субоч, М.С. Товбис \\ Сибирский государственный университет науки \\ и технологий им. академика М.Ф. Решетнева \\ Россия, 660037, Красноярск, \\ пр. имени газетье «Красноярский рабочий», 31
}

Для недавно синтезированных 3-арил-5-метоксиметил-4-амино-1Н-пиразолов проведена реакиия сульфонилирования по аминогруппе п-ацетамидобензолсульфохлоридом. результате впервые получены сульфаниламидные производные замещенных аминопиразолов, идентифицированные с использованием ИК-, ЯМР' Н-спектроскопии и масс-спектрометрии.

Ключевые слова: Пиразол, аминопиразол, сульфаниламид, сульфонилирование, ЯМР'H-, ИКспектроскопия, масс-спектрометрия.

\section{Введение}

Сульфаниламидные препараты являются основными лекарственными средствами, позволившими впервые проводить успешную профилактику и лечение разнообразных бактериальных инфекций [1-3]. В настоящее время синтезировано множество новых сульфаниламидных лекарственных веществ, однако из-за привыкания микроорганизмов к их действию постоянно приходится применять все новые и новые препараты. Следовательно, синтез новых веществ подобного строения - актуальная задача.

На кафедре органической химии и технологии органических веществ СибГУ им. Решетнева ранее был синтезирован ряд аминопиразолов с арильными, алкоксильными и алкильными заместителями [4] и доказана их фармакологическая активность [5].

Настоящая статья посвящена синтезу ранее неизвестных сульфаниламидных производных аминопиразолов, обладающих потенциальной биологической активностью. Для этого нами были синтезированы аминопиразолы с различными заместителями и после обработки $n$-ацетамидобензолсульфохлоридом были впервые выделены сульфаниламидные производные аминопиразолов, доказано их строение с использованием современных физических методов анализа.

\section{Результаты и их обсуждение}

Недавно были синтезированы нитрозопиразолы 2 (рис. 1) по реакции циклоароматизации изонитрозо- $\beta$-дикетонов с общей формулой 1 с гидразингидратом в минимальном объеме спиртового раствора; при восстановлении нитрозопиразолов 2 гидразингидратом в хлористом метилене на катализаторе $\mathrm{Pd} / \mathrm{C}$ получили соответствующие аминопроизводные 3 [4].

$$
-241-
$$


В настоящей работе мы провели реакцию сульфонилирования аминопиразолов 3a-d и получили сульфаниламидные производные 4а-d с выходами от 55-79 \% в виде белых либо светлобежевых кристаллов с высокими температурами плавления. Строение синтезированных веществ доказывали с помощью ИК-, ЯМР'Н-спектров и масс-спектрометрии. В ИК-спектрах всех соединений присутствовали валентные колебания $\mathrm{S}=\mathrm{O}$-связей сульфонамидных групп в области 1153-1163 см-1. В масс-спектрах соединений (4a-d) имелись сигналы, соответствующие молекулярному иону $[\mathrm{M}]^{+}$и ионам $[\mathrm{M}+1]^{+},[\mathrm{M}+2]^{+}$, соотношение которых подтверждает состав, соответствующий рассчитанному. Ниже приведена вероятная схема фрагментации молекул

$$
\begin{aligned}
& \text { a) } \mathrm{Ar}=4-\mathrm{ClPh}_{2}, \mathrm{Alk}=\mathrm{CH}_{2} \mathrm{OCH}_{3} \\
& \text { b) } \mathrm{Ar}=\mathrm{C}_{6} \mathrm{H}_{5}, \mathrm{Alk}=\mathrm{CH}_{2} \mathrm{OCH}_{3} \\
& \text { c) } \mathrm{Ar}=\mathrm{C}_{10} \mathrm{H}_{7}, \mathrm{Alk}=\mathrm{CH}_{2} \mathrm{OCH}_{3} \\
& \text { d) } \mathrm{Ar}=\mathrm{CH}_{3}, \mathrm{Alk}=\mathrm{CH}_{3}
\end{aligned}
$$

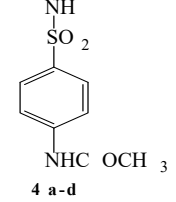

Рис. 1. Схема получения сульфонилированных производных аминопиразолов

Fig. 1. Scheme for obtaining sulfonyl derivatives of aminopyrazoles

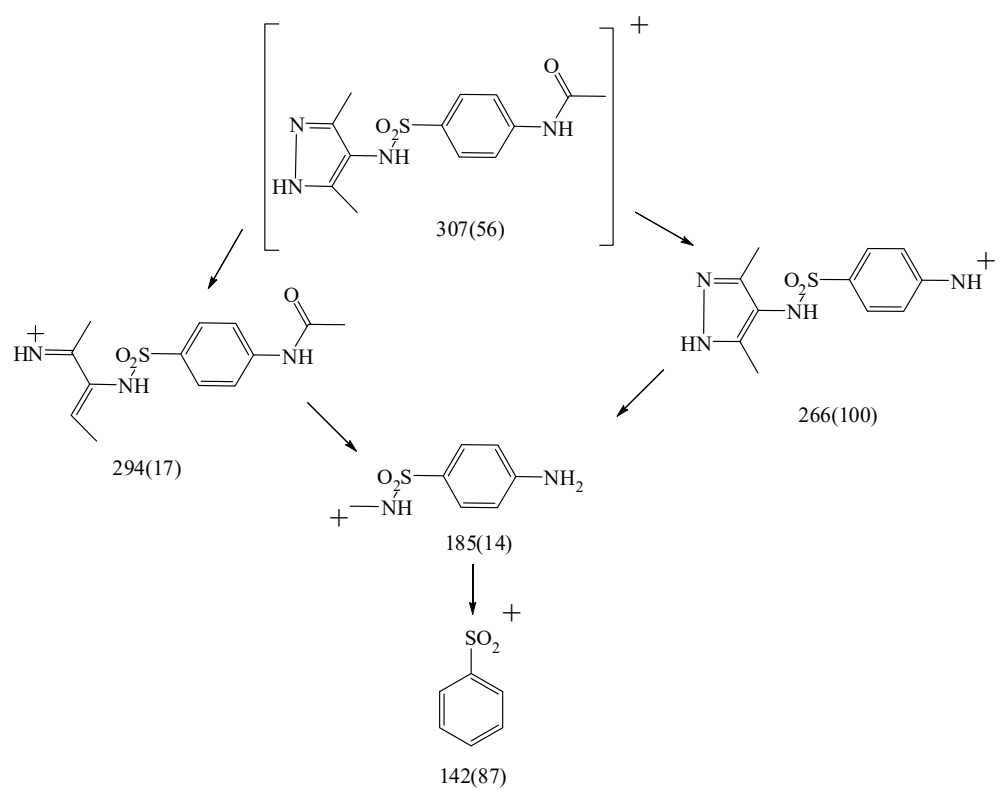

Рис. 2. Схема фрагментационого распада N-(4-(N-(3,5-диметил-1Н-пиразол-4-ил)сульфамоил)фенил) ацетамида (4d)

Fig. 2. Scheme of the fragmentation decomposition of N-(4-(N-(3,5-dimethyl-1H-pyrazol-4-yl)sulfamoyl)phenyl) acetamide $(4 \mathrm{~d})$ 


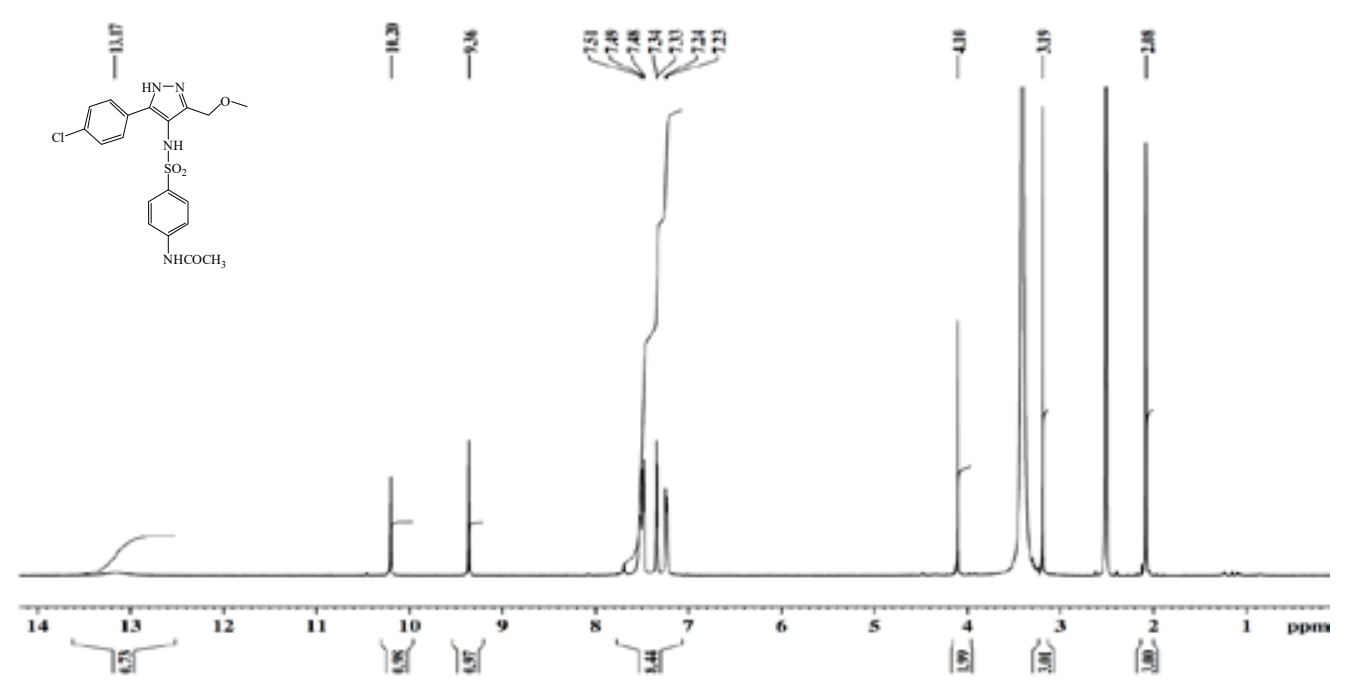

Рис. 3. ЯМР¹Н-спектр N-(4-(N-(5-(4-хлорфенил)-3-(метоксиметил)-1Н-пиразол-4-ил)сульфамоил)фенил) ацетамида

Fig. 3. NMR ${ }^{1} \mathrm{H}$-spectrum of N-(4-(N-(5-(4-chlorophenyl)-3-(methoxymethyl)-1H-pyrazol-4-yl)sulfamoyl)phenyl) acetamide

соединения (4d) в результате ионизации электроспреем при применении метода ВЭЖХ-МС [6, 7]. Для соединений $(4 \mathrm{a}, \mathrm{b})$ картина выглядела аналогично.

Важнейшая информация была получена по итогам записи и анализа ЯМР'Н-спектров. Так,

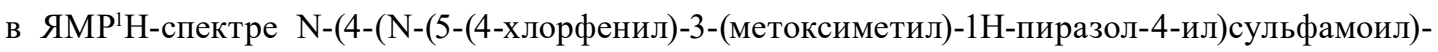
фенил)ацетамида, приведенного на рис. 3, присутствует сигнал в области 2.08 м.д., соответствующий протонам метильной группы в составе ацетильного заместителя. Протоны метоксиметильного заместителя представлены двумя синглетами с хим. сдвигами 3.19 м.д. для метильной и 4.10 м.д. для метиленовой групп. В области от 7.23 до 7.51 м.д. регистрируется мультиплет, принадлежащий протонам двух замещенных фенильных колец. Синглет с хим. сдвигом 9.36 м.д. принадлежит атому водорода ацетамидного заместителя, а синглет в области 10.20 м.д. - протону сульфамидной группы. В области слабого поля наблюдается синглет в области 13.17 м.д. - сигнал протона пиразольного кольца.

В ЯМР ${ }^{1}$-спектре N-(4-(N-(3-(метоксиметил)-5-фенил-1Н-пиразол-4-ил)сульфамоил)фенил)ацетамида на рис. 4 протоны метильной группы ацетамидного фрагмента представлены в виде синглета с хим. сдвигом 2.08 м.д. Сигналы в виде синглетов с хим. сдвигами 3.17 и 4.05 м.д. соответствуют метильной и метиленовой группам в составе метоксиметильного заместителя. В области 7.23-7.53 м.д. находится мультиплет ароматических протонов. Синглет в области 9.33 - протон ацетамидной группы. Атом водорода сульфамидного фрагмента дает синглет с хим. сдвигом 10.19 м.д., а протон пиразольного кольца представлен синглетом в области 13.07 м.д.

В ЯМР'Н-спектре N-(4-(N-3-(метоксиметил)-5-(нафталин-2-ил)-1Н-пиразол-4-ил)сульфамоил)фенил)ацетамида на рис. 5 в области 1.99 м.д. присутствует сигнал в виде синглета, соответствующий протонам метильной группы в составе ацетамидного заместителя. Синглет в области 3.23 м.д. принадлежит протонам метильной группы, а синглет с хим. сдвигом 


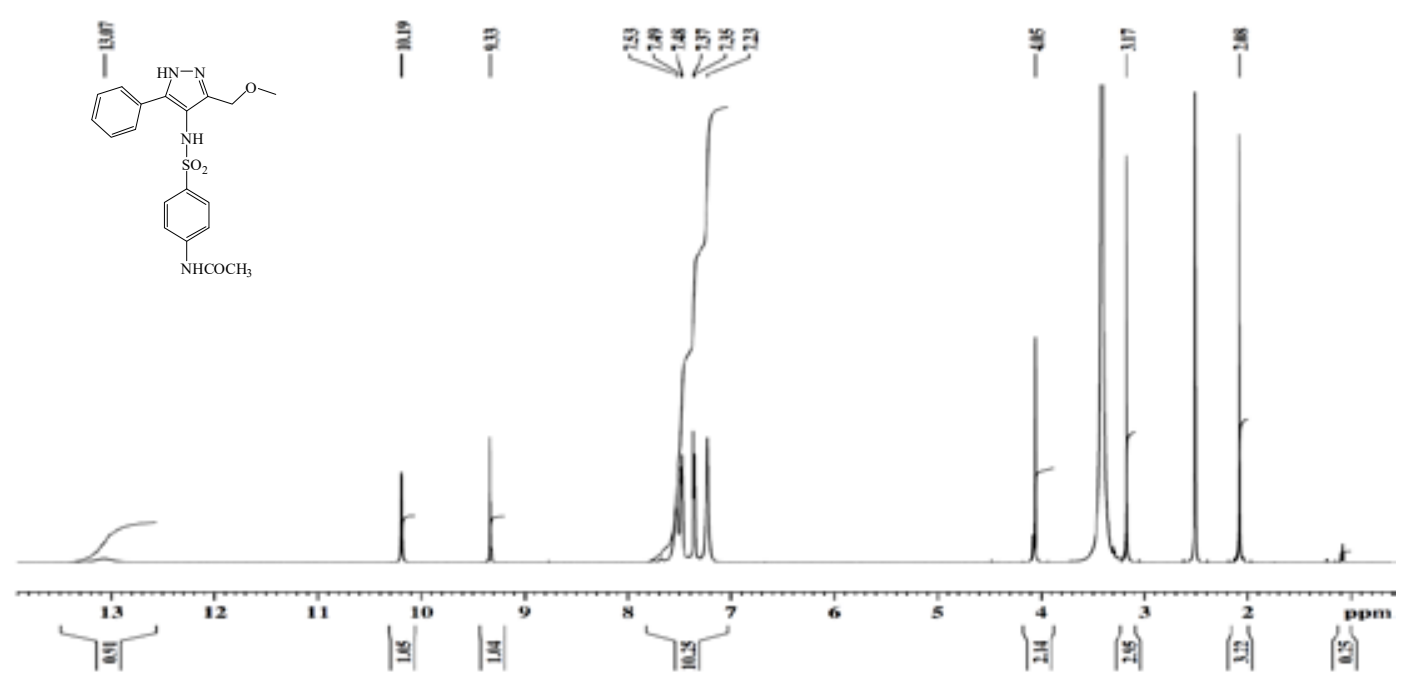

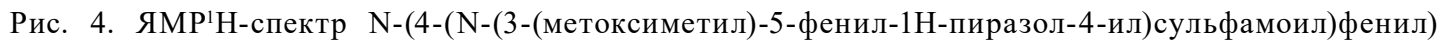
ацетамида

Fig. 4. NMR ${ }^{1} \mathrm{H}$ spectrum of N-(4-(N-(3-(methoxymethyl)-5-phenyl-1H-pyrazole-4-yl)sulfamoyl)phenyl) acetamide

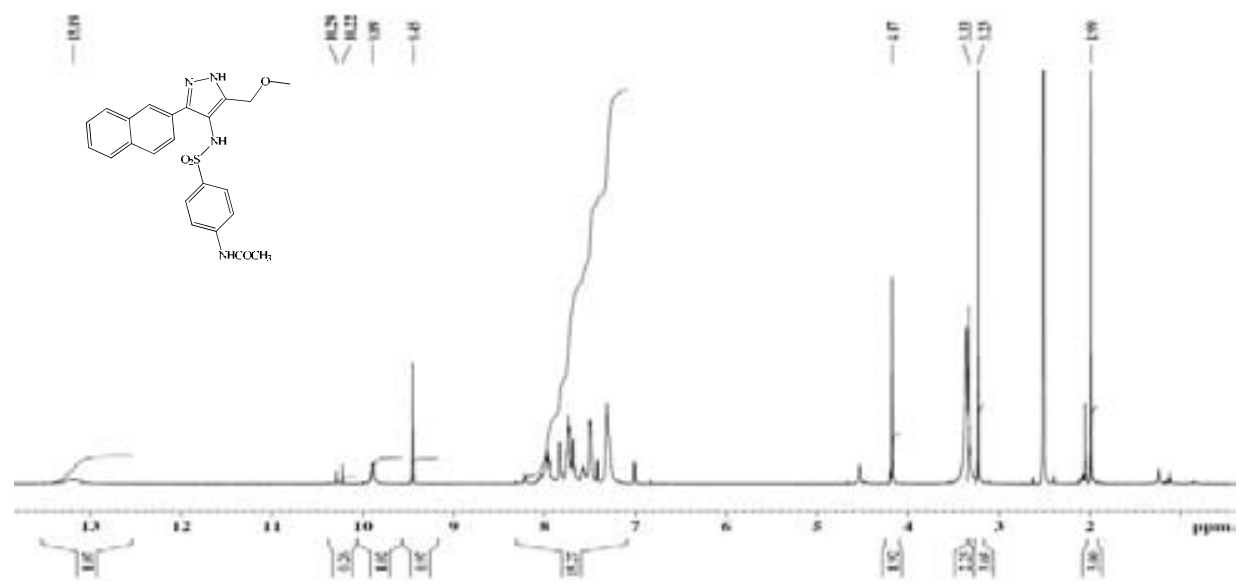

Рис. 5. ЯМР ${ }^{1}$-спектр N-(4-(N-3-(метоксиметил)-5-(нафталин-2-ил)-1Н-пиразол-4-ил)сульфамоил)фенил) ацетамида

Fig. 5. NMR ${ }^{1} \mathrm{H}$ spectrum N-(4-(N-3-(methoxymethyl)-5-(naphthalen-2-yl)-1H-pyrazol-4-yl)sulfamoyl)phenyl) acetamide

4.17 м.Д. - протонам метиленовой группы в составе метоксиметильного заместителя. Протоны ароматических колец дают мультиплет в области от 7.4 до 8.3 м.д. Сигнал в виде синглета в области 9.45 м.д. соответствует протону ацетамидной группы. Атом водорода сульфамидного фрагмента соответствует синглету в области 9.89 м.д. В области слабого поля (13.19 м.д.) расположен синглет, характерный для атома водорода пиразольного кольца.

ЯМР ${ }^{1} \mathrm{H}-$ спектр N-(4-(N-(3,5-диметил-1Н-пиразол-4-ил)сульфамоил)фенил)ацетамида приведен на рис. 6. В области сильного поля в спектре отчетливо видны два сигнала в виде синглетов с хим. сдвигами 1.86 и 2.09 м.д., первый из которых соответствует шести протонам двух 


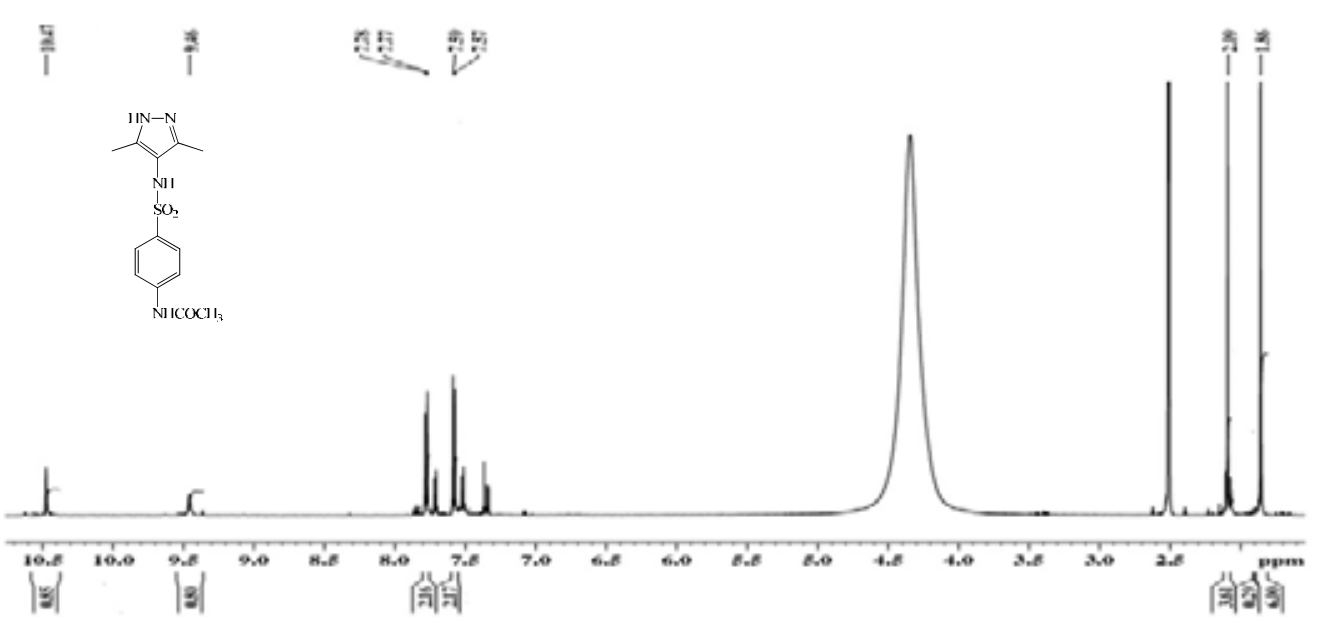

Рис. 6. ЯМРㄹ-спектр N-(4-(N-(3,5-диметил-1Н-пиразол-4-ил)сульфамоил)фенил)ацетамида

Fig. 6. NMR ${ }^{1} \mathrm{H}$ spectrum of N-(4-(N-(3,5-dimethyl-1H-pyrazol-4-yl)sulfamoyl)phenyl)acetamide

метильных групп при пиразольном кольце, второй - протонам метильной группы ацетамидного заместителя. Протоны ароматического кольца представлены двумя дублетами в области 7.57-7.59 и 7.77-7.78 м.д. Сигнал в области 9.46 м.д. в виде синглета принадлежит протону при атоме азота ацетамидной группы. Протон, связанный с атомом азота при сульфамидной группе, представлен в области слабого поля в виде синглета 10.47 м.д.

\section{Экспериментальная часть}

Спектры ЯМР регистрировали на приборе Bruker Avance III $600 \mathrm{MHz}$ Центра коллективного пользования Красноярского научного центра СО РАН.

Запись масс-спектров проводилась на приборе Shimadzu LC/MS-2020 с колонкой RAPTOR ARC-18 100. Хроматографирование проводили в изократическом режиме при температуре $35{ }^{\circ} \mathrm{C}$ в термостатируемой колонке. Масс-спектры получали прямым вводом образца и элюата, подаваемого хроматографом со скоростью $0,001 \mathrm{~cm}^{3} /$ мин, с ионизацией на электронапылительном источнике (ESI). Были выбраны следующие условия масс-детектирования: положительная и отрицательная поляризации, напряжение электроспрея 6 кВ, потенциал декластеризации и потенциал ввода - 60В при давлении газа завесы 5,0 л/мин и газа распыления 5,0 л/мин $[6,7]$. Диапазон сканирования составлял 20-500 Да.

ИК-спектры получены на ИК-микроскопе SpecTRA TECH InspectIR на базе ИК-Фурьеспектрофотометра Impact 400. Пробу вещества помещали на позолоченную пластину, раскатывали роликовым ножом, помещали на столик микроскопа и снимали спектр НПВО. Детектор MCT/A, объектив Si Caplugs, диапазон волновых чисел 4000-650 $\mathrm{cm}^{-1}$, разрешение $1.928 \mathrm{~cm}^{-1}$, количество сканирований 64, программное обеспечение OMNIC 5.1 E.S.P.

$N$-(4-(N-(5-(4-хлорфенил)-3-(метоксиметил)-1Н-пиразол-4-ил)сульфамоил)фенил)ацетамид (4a). 0,1 г (0,23 ммоль) амина растворяли в 6 мл воды. После растворения небольшими порциями попеременно добавляли 0,1 г (0,43 ммоль) хлорангидрида $n$-ацетаминобензолсульфокислоты и 0,032 г (0,30 ммоль) соды при непрерывном перемеши- 
вании и поддержании температуры $30^{\circ} \mathrm{C}$. Добавив расчетное количество хлорангидрида и соды, увеличивали температуру до $60^{\circ} \mathrm{C}$ и перемешивали смесь в течение двух часов. Затем охлаждали и добавляли соляную кислоту при комнатной температуре. Перемешивали в течение 30 мин, отфильтровывали и промывали водой до нейтральной среды. Выход: 0,17 г (69 \%), $\mathrm{T}_{\text {пл. }}=186-188{ }^{\circ} \mathrm{C}$. ИК-спектр, $v, \mathrm{~cm}^{-1}: 1596,1543\left(\mathrm{C}_{6} \mathrm{H}_{4}\right), 1161\left(\mathrm{SO}_{2}\right), 1091$ (СОС). Спектр ЯМР ${ }^{1} \mathrm{H}$, $\delta$, м. д.: 2.08 с (3H, $\left.\mathrm{CH}_{3} \mathrm{C}(\mathrm{O})\right), 3.19$ с $\left(3 \mathrm{H}, \mathrm{CH}_{3} \mathrm{O}\right), 4.10$ с $\left(2 \mathrm{H}, \mathrm{CH}_{2}\right), 7.23-7.51$ м $\left(8 \mathrm{H}_{\text {apom. }}\right), 9.36 \mathrm{c}(1 \mathrm{H}$, $\mathrm{NHCO}), 10.20$ с (1H, $\left.\mathrm{NHSO}_{2}\right), 13.17$ с (1H, NH). Спектр ЯМР ${ }^{13} \mathrm{C}, \delta$, м. д.: 24.38, 57.93, 112.73, 118.42,

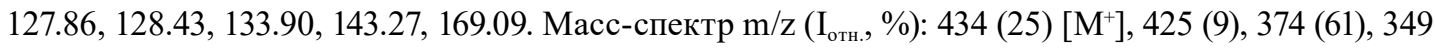
(25), 273 (100), 194 (96), 152 (14).

\section{N-(4-(N-(3-(метоксиметил)-5-фенил-1H-пиразол-4-ил)сульфамоил)фенил)ацетамид}

(4b). 0.1 г (0,25 ммоль) амина растворяли в 6 мл воды. После растворения небольшими порциями попеременно добавляли 0.14 г (0,60 ммоль) хлорангидрида $n$-ацетаминобензолсульфокислоты и 0.04 г (0,38 ммоль) соды, как в предыдущем примере. Далее обрабатывали аналогично 4а. Выход: 0,13 г. (62 \%), $\mathrm{T}_{\text {пл. }}=138-140{ }^{\circ} \mathrm{C}$. ИК-спектр, $v$, см$^{-1}: 1591,1530\left(\mathrm{C}_{6} \mathrm{H}_{5}\right), 1153\left(\mathrm{SO}_{2}\right), 1074$ (COC). Спектр ЯMP'H, $\delta$, м. д.: 2.08 с (3H, $\left.\mathrm{CH}_{3} \mathrm{C}(\mathrm{O})\right), 3.17$ с (3H, $\left.\mathrm{CH}_{3} \mathrm{O}\right), 4.05$ с $\left(2 \mathrm{H}, \mathrm{CH}_{2}\right), 7.23-7.53$ м $\left(9 \mathrm{H}_{\text {аром. }}\right), 9.33$ с (1H, NHCO $), 10.19$ с $\left(1 \mathrm{H}, \mathrm{NHSO}_{2}\right), 13.07$ с (1H, NH). Спектр ЯМР ${ }^{13} \mathrm{C}, \delta$, м. д.: 24.37, $57.87,112.56,118.48,126.89,127.87,128.20,134.03,143.11,169.12$. Масс-спектр m/z ( $\left.\mathrm{I}_{\text {отн. }} \%\right): 400$ (38) $\left[\mathrm{M}^{+}\right], 390$ (5), 357 (100), 328 (6), 313 (12), 297 (14), 183 (13).

N-(4-(N-3-(метоксиметил)-5-(нафталин-2-ил)-1Н-пиразол-4-ил)сульфамоил) фенил)ацетамид (4c). 0.1 г (0,23 ммоль) амина растворяли в 6 мл воды. После растворения небольшими порциями попеременно добавляли 0.1 г (0,43 ммоль) хлорангидрида $n$-ацетаминобензолсульфокислоты и 0.037 г (0,35 ммоль) соды, как в предыдущем примере. Далее обрабатывали аналогично 4а. Выход: 0,11 г (55 \%), $\mathrm{T}_{\text {пл. }}=226-228^{\circ} \mathrm{C}$. ИК-спектр, $v, \mathrm{~cm}^{-1}$ : 1594, $1543\left(\mathrm{C}_{10} \mathrm{H}_{7}\right), 1153\left(\mathrm{SO}_{2}\right), 1091$ (СОC). Спектр ЯМР ${ }^{1} \mathrm{H}, \delta$, м. д.: 1.99 с (3H, $\left.\mathrm{CH}_{3} \mathrm{C}(\mathrm{O})\right), 3.23$ с $\left(3 \mathrm{H}, \mathrm{CH}_{3} \mathrm{O}\right), 4.17$ c $\left(2 \mathrm{H}, \mathrm{CH}_{2}\right), 7.4-8.3$ м $\left(\mathrm{H}_{\text {aром. }}\right), 9.45$ c $(1 \mathrm{H}, \mathrm{NHCO}), 9.89$ c $\left(1 \mathrm{H}, \mathrm{NHSO}_{2}\right), 13.19 \mathrm{c}$ $(1 \mathrm{H}, \mathrm{NH})$.

N-(4-(N-(3,5-диметил-1Н-пиразол-4-ил)сульфамоил)фенил)ацетамид $\quad$ (4d). $1.0 \quad$ г (0,32 ммоль) амина растворяли в 9 мл воды. После растворения небольшими порциями попеременно добавляли 2.3 г (0,99 ммоль) хлорангидрида $n$-ацетаминобензолсульфокислоты и 0.69 г (6,51 ммоль) соды, как в предыдущем примере. Далее обрабатывали аналогично $4 \mathbf{a}$. Выход: 0,89 г (79 \%), $\mathrm{T}_{\text {пл. }}=202-204{ }^{\circ} \mathrm{C}$. ИК-спектр, $v, \mathrm{~cm}^{-1}$ : 1586, $1526\left(\mathrm{C}_{6} \mathrm{H}_{4}\right), 1158\left(\mathrm{SO}_{2}\right), 1092$ (COC). Спектр ЯMP' $\mathrm{H}, \delta$, м. д.: 1.86 с (6H, $\left.2 \mathrm{CH}_{3}\right), 2.09$ с $\left(\mathrm{CH}_{3} \mathrm{C}(\mathrm{O})\right), 7.57-7.78$ м $\left(4 \mathrm{H}_{\text {аром. }}\right), 9.46 \mathrm{c}$

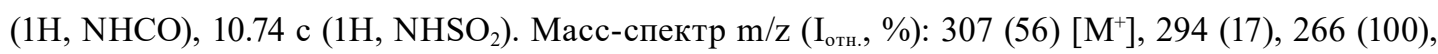
183 (14), 142 (87).

\section{Список литературы}

1. Машковский М.Д. Лекарственные средства. В 2-х частях. 14-е изд., перераб. и доп. М.: Медицина, 2000. Т. 1, 736 с. Т. 2, 688 с. [Mashkovsky M.D. Medicinal products. In 2 parts. 14 th ed., rev. M .: Medicine, 2000. Vol. 1, 736 p. Vol. 2, 688 p. (In Russ.)]

2. Солдунов Г.Н. Сульфаниламидные препараты. Учебное пособие по фармацевтической химии ЦМС ВолгГМУ, 2012. 57 c. [Soldunov G.N. Sulfanilamide preparations. A manual on pharmaceutical chemistry CMS VolgGMU, 2012. 57 p. (In Russ.)] 
3. Беликов В.Г. Фармацевтическая химия. Учебное пособие по фармацевтической химии. М.: МЕДпресс-информ, 2007. 216 с. [Belikov V.G. Pharmaceutical Chemistry, Manual on Pharmaceutical Chemistry. M.: MEDpress-Inform, 2007. 216 p. (In Russ.)]

4. Ефимов В.В., Любяшкин А.В., Субоч Г.А., Товбис М.С. Синтез новых алкоксиметилзамещенных 4-амино-1Н-пиразолов и их ацилирование. Журнал органической химии 2016. Т. 56, C. 52-54 [Efimov V.V., Lyubiashkin A.V., Suboch G.A., Tovbis M.S. Synthesis of new alkoxymethylsubstituted 4-amino-1H-pyrazoles and their acylation. Journal of Organic Chemistry 2016. Vol. 56, P. 52-54. (In Russ.)]

5. Любяшкин А.В., Поваров И.Г., Субоч Г.А., Товбис М.С. Ацилирование и сульфонилирование некоторых азотосодержащих соединений: Монография: СибГУ им. Решетнева 2018. 184 c. [Lyubiashkin A.V., Povarov I.G., Suboch G.A. Tovbis M.S. Acylation and sulfonylation of some nitrogen-containing compounds: Monograph of Reshetnev SibSU 2018. 184 p. (In Russ.)]

6. Бочкарев В.Н., Поливанов А.Н., Фалько В.С. Масс-спектры положительных и отрицательных ионов линейных метил фенилсилоксанов. Журнал общей химии 1978. Т. 48, С. 858-861. [Bochkarev V.N., Polivanov A.N., Fal'ko V.S. Mass spectra of positive and negative ions of linear methyl phenylsiloxanes. Log general chemistry 1978. T. 48, C. 858-861. (In Russ.)]

7. Chinnaraja D., Rajalakshmi R., Latha V., Manikandan H. Synthesis, spectral characterization and biological evaluation of 1-thiocarbamoyl-3-phenyl-5-hydroxy-5-(-2-pyridyl)-4-pyrazolines via michael addition. Journal of Saudi Chemical Society 2016, Vol. 20, P. 599-605. doi:10.1016/j. jscs.2013.04.006 